\title{
Medical Illnesses among Chronic Psychiatric Inpatients in Taif Mental Hospital, Taif, Saudi Arabia
}

Jaber Sharaheeli ${ }^{*}$ and Randa Nooh ${ }^{2}$

${ }^{1}$ Field Epidemiology Training Program, College of Medicine, King Saud University and General Directorate of Environmental and Occupational Health, Ministry of Health, Saudi Arabia

${ }^{2}$ Consultant of Epidemiology, Field Epidemiology Training Program, Ministry of Health, Saudi Arabia

\begin{abstract}
Background/Introduction: Chronic psychiatric inpatients are prone to various medical illnesses because there multiple risk factors to develop such illnesses. Diabetes mellitus, heart diseases and hypertension have particular significance.

Objectives: This study aimed to assess the pattern of medical illnesses namely diabetes mellitus, heart diseases and hypertension among chronic psychiatric inpatients.

Methodology: A cross-sectional study was conducted. This study collected data through a retrospective chart review. Epi-Info was used for data entry and analysis.

Results: We analyzed 465 permanent (no plan for future discharge) psychiatric inpatients, $76.8 \%$ males, $89.2 \%$ of all patients fell within one age group of $41-50$ years. $72.5 \%$ schizophrenics, $20.2 \%$ mentally retarded and $7.3 \%$ other psychiatric diagnoses. $30.1 \%$ had at least one associated medical comorbidity while Schizophrenia has the highest comorbidity $(82.9 \%)$. The pattern of comorbidities among the population of psychiatric inpatients was: heart diseases $(49.3 \%)$, hypertension $(25 \%)$, and diabetes mellitus $(25.7 \%)$.
\end{abstract}

Conclusion: Medical comorbidity was present among psychiatric inpatients in Taif mental hospital mainly in schizophrenics. Heart diseases are the commonest.

Keywords: Medical illnesses; Mental illness; Chronic psychiatric inpatients; Altaif mental hospital; Saudi Arabia

\section{Introduction}

The medical comorbidity of psychiatric patients is a topic of increasing significance and there is a need to indicate as how common is the comorbidity [1]. The possible reasons for this increased comorbidity may include a genetic relationship between the mental and medical disorders [2]. Both conventional and novel antipsychotic agents are associated with weight gain [3]. Patients with schizophrenia treated with atypical antipsychotics had a moderately increased risk of DM [4]. The use of psychotropics contributes to weight gain, which is associated with diabetes and hypertension. Smoking in psychiatric patients contributes to heart diseases. Physical inactivity contributes to hypertension and heart disease. Those with a comorbid substance use disorder had the highest risk for some medical disorders e.g. heart diseases [5]. WHO has suggested that persons with mental disorders have a right to healthcare comparable to that received by the general population [6]. Not only medical illnesses cause cognitive impairment, but cognitive impairment may also lead to the onset and exacerbation of these medical comorbidities among patients with schizophrenia [7]. Patients with schizophrenia have high rates of under-diagnosed, under-treated and under-documented medical problems [8]. Medical illness complicates the treatment of mental illness, and patients with severe mentalillness die at an earlier age from physical health problems than do those without mental illness [9]. Elderly psychiatric patients and patients with organic mental disorders e.g. dementia present the greatest risk of comorbid physical illness, with high prevalence rates of such illnesses [10]. $72 \%$ of psychiatric inpatients have medical comorbidity [11]. Prevalence of hypertension, diabetes mellitus and cardiovascular diseases among psychiatric patients are $10.2 \%, 7.36 \%$ and $8.77 \%$ respectively [5]. The overall prevalence of diabetes and impaired glucose tolerance in schizophrenic patients was $16.0 \%$ and $30.9 \%$, respectively [12]. The prevalence of diabetes mellitus in schizophrenia patients in different age groups (15-25: 2\%; 25-35: 3.2\%; 35-45: 6.1\%; 45-55: 12.7\%; 44-65: 25\%) [13]. Cardiovascular mortality was 6.6 times higher among psychiatric patients than the general population. Cardiovascular mortality in Schizophrenia increased from 1976 to 1995, with the greatest increase in Standardized Mortality Ratios in men from 1991 to 1995 [14]. Prevalence of diabetes mellitus in bipolar affective disorders is $19 \%$. Prevalence of cardiovascular diseases in bipolar affective disorders is $44 \%$. Prevalence of hypertensions in schizophrenia is $35 \%$ [15]. Depressed individuals have a $60 \%$ increased risk of developing diabetes [16]. 13.3\% of mental retardation cases have both a psychiatric as well as medical illness. Psychiatric comorbidity presents in $56.67 \%$ of mental retardation patients. $35.0 \%$ of mental retardation patients have medical disease comorbidity. $41.18 \%$ of mentally-retarded patients with a psychiatric disorder had mild mental retardation and $29.41 \%$ of mentally-retarded patients had severe to profound mental retardation, whereas $23.81 \%$ of mentally-retarded patients with a medical disease had mild mental retardation and $57.14 \%$ had severe to profound mental retardation. In mentally-retarded patients who had a psychiatric comorbidity, a medical disease was present in $23.53 \%$ patients, as compared to $50.0 \%$ patients in those who had no psychiatric comorbidity [17]. I did not find researches in Saudi Arabia shed the light on the comorbidity between mental and medical illnesses. Therefore, there a need for such studies in Saudi Arabia.

*Corresponding author: Jaber Sharaheeli, Field Epidemiology Training Program Resident, King Saud University, Riyadh, P.O. Box: 70047, Saudi Arabia, Tel: 966503946914; Fax: 966114960163; E-mail: aboamal1416@hotmail.com

Received: April 20, 2016; Accepted: June 24, 2016; Published: June 30, 2016

Citation: Sharaheeli J, Nooh R (2016) Medical Illnesses among Chronic Psychiatric Inpatients in Taif Mental Hospital, Taif, Saudi Arabia. J Psychiatry 19: 375 doi:10.4172/2378-5756.1000375

Copyright: (c) 2016 Sharaheeli J, et al. This is an open-access article distributed under the terms of the Creative Commons Attribution License, which permits unrestricted use, distribution, and reproduction in any medium, provided the original author and source are credited. 


\section{Objectives}

This study aimed to assess the pattern of three medical illnesses; diabetes mellitus, heart diseases and hypertension among chronic psychiatric inpatients in Taif mental hospital, Taif, Saudi Arabia.

\section{Methodology}

\section{Study design}

A cross-sectional study was conducted at Taif mental hospital, April and May 2008, in Taif city, Saudi Arabia among the chronic psychiatric inpatients by a retrospective chart review.

\section{Study population}

The study population consists of all chronically admitted psychiatric patients in Taif mental hospital who had been admitted for at least one year and with no plan for future discharge (permanent), with or without medical condition. That means they are permanent to stay in the hospital without discharge due to different reasons such as no social support or forensic issues (homicide).

\section{Sampling procedure}

465 patients who fulfill the criteria were included in this study.

\section{Data collection}

Data were collected from chart reviews to complete the pre-designed questionnaire that includes information concerning demographic data, psychiatric diagnosis and medical comorbidity. The principal investigator conducted the data collection because nobody agreed to help him and no financial support for this effort.

\section{Analysis plan}

The Epi-Info was used for data entry and analysis. The data were analyzed to estimate the prevalence of each psychiatric disorder in addition to the prevalence medical comorbidities and their distribution among them. The frequencies and distribution of mental illnesses by gender and age group were calculated. Psychiatric disorders are categorized into three categories; schizophrenia, mental retardation and other psychiatric diagnoses. I combined other psychiatric diagnoses into one group to make figures significant because some disorders have very small percentage.

\section{Ethics}

Ethical and administrative approvals were obtained from field epidemiology training program and the Ministry of Health committee. Regarding consent; no consent was required from the patients because the data were collected from medical files. The study involved no risk to the subjects. The waiver or alteration of consent did not adversely affect the rights and welfare of the subjects. Whenever appropriate, the subjects will be provided with additional pertinent information after participation. Regarding confidentiality; the confidentiality of personal data was maintained. The information was gathered and recorded by the principal investigator. No other individuals participated in data collection or had access to the medical files except the supervisor. Names and file numbers did not appear in the study. Thus, the subjects could not be identified. Codes were given to the files (e.g., \#10 in the sample or the last 3 digits of the file number).

\section{Results}

A total of 465 permanent psychiatric inpatients in Taif mental hospital during the study period included in the study. Every patient had been admitted for at least one year.

\section{Socio-demographic characteristics}

All psychiatric inpatients were distributed over 13 wards (4 female wards and 9 male wards, including two forensic wards). There are 357 male patients and 108 female patients. There are 28 patients within $\geq 30$ years age group, 91 within $31-40$ years, 171 within $41-50$ years, 101 within $51-60$ years, 53 within $61-70$ years and 21 over 70 years age groups (Tables 1 and 2).

\section{Characteristics of mental disorders}

Among the total of 465 permanent psychiatric inpatients in Taif mental hospital, (72.5\%) had been diagnosed as schizophrenics, (20.2\%) as mentally retarded and (7.3\%) with other psychiatric diagnoses, which included: Bipolar Affective Disorders (1.1\%), Major Depressive Disorders (0.4\%), Dementia (0.4\%), mental disorders due to general medical conditions $(0.2 \%)$, mental disorders due to substance abuse (0.6\%), Personality Disorders (1.3\%), Schizoaffective disorders $(1.1 \%)$ and $(2.2 \%)$ various mental disorders (including delusional disorders, not otherwise specified ....etc.) (Table 3).

Among the 357 male patients, there were (79.8\%) schizophrenics, (13.2\%) mentally retarded and (7.0\%) with other psychiatric diagnoses. Other psychiatric illnesses comprise bipolar affective disorders, major depressive disorders, dementia, mental disorders due to general medical conditions, mental disorders due to substance, personality disorders, schizoaffective disorders and others. Among the 108 female patients, there were $(48.1 \%)$ schizophrenics, $(43.5 \%)$ mentally retarded and $(8.4 \%)$ with other psychiatric diagnoses (Table 1).

When psychiatric illnesses were categorized by age group: within the age group less than or equal to 30 years, there were $(67.86 \%)$ diagnosed with schizophrenia, (21.43\%) mental retardation and (10.71\%) other psychiatric illnesses; Within the age group 31-40 years, there were $(73.63 \%)$ diagnosed with schizophrenia, (19.78\%) mental retardation and (6.59\%) other psychiatric illnesses; Within the age group 41-50 years, there were (70.76\%) diagnosed with schizophrenia, (22.8\%) mental retardation and (6.43\%) other psychiatric illnesses; Within the age group 51-60 years, there were (72.28\%) diagnosed with schizophrenia, (17.82\%) mental retardation and $(9.9 \%)$ other psychiatric illnesses; Within the age group 61-70 years, there were (77.36\%) diagnosed with schizophrenia, (16.98\%) mental retardation and $(5.66 \%)$ other psychiatric illnesses; among those over 70 years, there were (76.2\%) diagnosed with schizophrenia, (19.0\%) mental retardation and (4.8\%) other psychiatric illnesses (Table 2).

\section{Magnitude of comorbid medical illnesses (heart diseases, hypertension and diabetes mellitus) among psychiatric patients}

The overall medical comorbidities of the three selected medical illnesses among psychiatric inpatients was (30.1\%) of permanent psychiatric inpatients included in the study and had at least one medical illness of the three intended illnesses. Among patients with schizophrenia, there were (34.4\%) associated with at least one medical illness. Among patients with mental retardation, there were $(19.1 \%)$ associated with at least one medical illness. Among patients with other mental illnesses, there were $(17.7 \%)$ associated with at least one medical illness (Table 4).

\section{Medical illness distribution by psychiatric diagnoses}

The pattern of the three medical comorbidities among the 
Citation: Sharaheeli J, Nooh R (2016) Medical Illnesses among Chronic Psychiatric Inpatients in Taif Mental Hospital, Taif, Saudi Arabia. J Psychiatry 19: 375 doi: $10.4172 / 2378-5756.1000375$

Page 3 of 4

\begin{tabular}{|c|c|c|c|}
\hline Psychiatric Diagnoses & Female & Male & Total \\
\hline Schizophrenia & $52(48.1 \%)$ & $285(79.8 \%)$ & $337(72.5 \%)$ \\
\hline Mental Retardation & $47(43.5 \%)$ & $47(13.2 \%)$ & $94(20.2 \%)$ \\
\hline Other Psychiatric Diagnoses & $9(8.4 \%)$ & $25(7.0 \%)$ & $34(7.3 \%)$ \\
\hline Total & $108(100.0 \%)$ & $357(100.0 \%)$ & $465(100.0 \%)$ \\
\hline
\end{tabular}

Table 1: Gender distribution of mental illnesses among chronic psychiatric inpatients in Taif mental hospital, Taif, Saudi Arabia.

\begin{tabular}{|c|c|c|c|c|}
\hline Age Group Schizophrenia & $\begin{array}{c}\text { Mental } \\
\text { Retardation }\end{array}$ & $\begin{array}{c}\text { Other Psychiatric } \\
\text { Diagnoses }\end{array}$ & Total \\
\hline$\leq 30$ & $19(67.86 \%)$ & $6(21.43 \%)$ & $3(10.71 \%)$ & $28(100.0 \%)$ \\
\hline $31-40$ & $67(73.63 \%)$ & $18(19.78 \%)$ & $6(6.59 \%)$ & $91(100.0 \%)$ \\
\hline $41-50$ & $121(70.76 \%)$ & $39(22.81 \%)$ & $11(6.43 \%)$ & $\begin{array}{c}171 \\
(100.0 \%)\end{array}$ \\
\hline $51-60$ & $73(72.28 \%)$ & $18(17.82 \%)$ & $10(9.9 \%)$ & $\begin{array}{c}101 \\
(100.0 \%)\end{array}$ \\
\hline $61-70$ & $41(77.36 \%)$ & $9(16.98 \%)$ & $3(5.66 \%)$ & $53(100.0 \%)$ \\
\hline$>70$ & $16(76.2 \%)$ & $4(19.0 \%)$ & $1(4.8 \%)$ & $21(100.0 \%)$ \\
\hline Total & $337(72.5 \%)$ & $94(20.2 \%)$ & $34(7.3 \%)$ & $\begin{array}{c}465 \\
(100.0 \%)\end{array}$ \\
\hline
\end{tabular}

Table 2: Mental illnesses distribution by age groups among chronic psychiatric inpatients in Taif mental hospital, Taif, Saudi Arabia.

\begin{tabular}{|c|c|c|}
\hline \multicolumn{2}{|r|}{ Psychiatric Diagnosis } & Frequency \& \% \\
\hline \multicolumn{2}{|r|}{ Schizophrenia } & $337(72.5 \%)$ \\
\hline \multicolumn{2}{|r|}{ Mental retardation } & $94(20.2 \%)$ \\
\hline \multirow{7}{*}{$\begin{array}{c}\text { Other } \\
\text { Psychiatric } \\
\text { Diagnosis } \mathrm{N}=34 \\
(7.3 \%)\end{array}$} & B.A.D (Bipolar Affective Disorders) & $5(1.1 \%)$ \\
\hline & M.D.D (Major Depressive Disorders) & $2(0.4 \%)$ \\
\hline & Dementia & $2(0.4 \%)$ \\
\hline & $\begin{array}{l}\text { MD/GMC (Mental Disorders due to } \\
\text { General Medical Conditions) }\end{array}$ & $1(0.2 \%)$ \\
\hline & $\begin{array}{c}\text { MD/Substance (Mental Disorders due to } \\
\text { Substance) }\end{array}$ & $3(0.6 \%)$ \\
\hline & P.D (Personality Disorders) & $6(1.3 \%)$ \\
\hline & S.A.D (Schizoaffective Disorders) & $5(1.1 \%)$ \\
\hline & Others & $10(2.2 \%)$ \\
\hline \multicolumn{2}{|r|}{ Total } & $465(100.0 \%)$ \\
\hline
\end{tabular}

Table 3: Distribution of mental disorders among chronic psychiatric inpatients in Taif mental hospital, Taif, Saudi Arabia.

psychiatric inpatients with comorbidity was as follows: (82.9\%) present in schizophrenia, $(12.9 \%)$ in mental retardation and $(4.2 \%)$ in other psychiatric mental disorders. Medical illnesses are $49.3 \%$ heart diseases, $25 \%$ hypertension and $25.7 \%$ diabetes mellitus. When the pattern of medical comorbidities was described by psychiatric diagnoses, it was found that: among schizophrenic patients $(51.7 \%)$ with heart diseases, (20.7\%) with hypertension and $(27.6 \%)$ with diabetes mellitus. Among mentally retarded patients (38.9\%) are with heart diseases, (50\%) with hypertension and (11.1\%) with diabetes mellitus. Among those patients are with other mental illnesses (33.3\%) with heart diseases, $(33.3 \%)$ with hypertension and (33.3\%) with diabetes mellitus (Table 5).

\section{Discussion}

It is noticed that, the prevalence of the three medical illnesses among chronic psychiatric inpatients represents a high figure $30.1 \%$

\begin{tabular}{|c|c|c|c|}
\hline \multirow{2}{*}{ Psychiatric Disorders } & \multicolumn{2}{|c|}{ Medical Comorbidity } & \multirow{2}{*}{ Total } \\
\cline { 2 - 3 } & Yes & No & \\
\hline Schizophrenia & $116(34.4 \%)$ & $221(65.6 \%)$ & $337(100.0 \%)$ \\
\hline Mental Retardation & $18(19.1 \%)$ & $76(80.9 \%)$ & $94(100.0 \%)$ \\
\hline Other Psychiatric Diagnoses & $6(17.7 \%)$ & $28(82.3 \%)$ & $34(100.0 \%)$ \\
\hline Total & $140(30.1 \%)$ & $325(69.9 \%)$ & $465(100.0 \%)$ \\
\hline
\end{tabular}

Medical comorbidity comprises only the three diseases (diabetes mellitus, hypertension and heart diseases)

Table 4: Frequency of medical comorbidity by mental illnesses among chronic psychiatric inpatients in Taif mental hospital, Taif, Saudi Arabia.

\begin{tabular}{|c|c|c|c|c|}
\hline $\begin{array}{c}\text { Medical } \\
\text { Illnesses }\end{array}$ & Schizophrenia & $\begin{array}{c}\text { Mental } \\
\text { Retardation }\end{array}$ & $\begin{array}{c}\text { Other } \\
\text { psychiatric } \\
\text { Diagnoses }\end{array}$ & $\begin{array}{c}\text { Total } \\
\text { N=182 }\end{array}$ \\
\hline Heart diseases & $60(51.7 \%)$ & $7(38.9 \%)$ & $2(33.3 \%)$ & $69(49.3 \%)$ \\
\hline Hypertension & $24(20.7 \%)$ & $9(50.0 \%)$ & $2(33.3 \%)$ & $35(25 \%)$ \\
\hline $\begin{array}{c}\text { Diabetes } \\
\text { mellitus }\end{array}$ & $32(27.6 \%)$ & $2(11.1 \%)$ & $2(33.3 \%)$ & $36(25.7 \%)$ \\
\hline Total & $116(82.9 \%)$ & $18(12.9 \%)$ & $6(4.2 \%)$ & $140(100 \%)$ \\
\hline
\end{tabular}

Table 5: Frequency of medical illnesses with known onset distributed by psychiatric illnesses among chronic psychiatric inpatients in Taif mental hospital, Taif, Saudi Arabia

but less than that of other studies [11,17]. This difference may be due to that, our study concentrated only on three groups of medical illnesses but other study considered all medical illnesses. They are higher among schizophrenic patients $(82.9 \%)$ than those in mental retardation and other psychiatric diagnoses [8]. Heart diseases prevalence is the highest among the three medical illnesses. They are approximately equal to both hypertension and diabetes mellitus. This is different from other studies [5]. Heart diseases are more comorbid with schizophrenia than other mental illnesses, while hypertension is higher among patients with mental retardation. Schizophrenia is the commonest mental disorder among psychiatric inpatients in Taif mental hospital. The study showed that, hypertension is less in schizophrenia as compared to other studies [15]. Diabetes mellitus prevalence is higher among patients of other psychiatric diagnoses than that in schizophrenia or mental retardation. This may be attributed to the presence of bipolar affective disorders and major depressive disorders among other psychiatric diagnoses group, although it is lower than its prevalence in depression when compared to other studies $[12,13,15,16]$. The three groups of medical illnesses have same prevalence among the patients labeled with other psychiatric diagnoses.

\section{Limitations}

The major limitation of this study is the use of secondary data in which the files are incomplete and inaccurate.

\section{Conclusion}

Heart diseases were the highest medical comorbidity among psychiatric inpatients who had medical comorbidity. They are more with schizophrenia which represented the commonest mental illness. Psychiatric inpatients should receive regular thorough medical assessment, particularly for heart diseases, hypertension and diabetes mellitus.

\section{Acknowledgements}

The authors are grateful for the great and anticipated help of Taif health affairs directorate, Taif mental hospital administration and everybody helped in this mission. 
Citation: Sharaheeli J, Nooh R (2016) Medical Illnesses among Chronic Psychiatric Inpatients in Taif Mental Hospital, Taif, Saudi Arabia. J Psychiatry 19: 375 doi:10.4172/2378-5756.1000375

Page 4 of 4

\section{Declaration of Interest}

The authors report no conflicts of interest.

\section{References}

1. Lyketsos CG, Dunn G, Kaminsky MJ, Breakey WR (2002) Medical comorbidity in psychiatric inpatients relation to clinical outcomes and hospital length of stay. Psychosomatics 43: 24-30.

2. Cassidy F, Ahearn E, Carroll BJ (1999) Elevated frequency of diabetes mellitus in hospitalized manic-depressive patients. Am J Psychiatry 156: 1417-1420.

3. Henderson DC, Copeland PM, Daley TB, Borba CP, Cather C, et al. (2005) A double-blind, placebo-controlled trial of sibutramine for olanzapine-associated weight gain. Am J Psychiatry 162: 954-962.

4. Ollendorf DA, Joyce AT, Rucker M (2004) Rate of new-onset diabetes among patients treated with atypical or conventional antipsychotic medications for schizophrenia. MedGenMed 6: 5 .

5. Dickey B, Normand ST, Weiss RD, Drake RE, Azeni H (2002) Medical morbidity, mental illness, and substance use disorders. Psychiatr Serv 53: 861-867.

6. Newcomer JW (2007) Metabolic syndrome and mental illness. Am J Manag Care 13: S170-S177.

7. Chwastiak LA, Rosenheck RA, Mcevoy JP, Keefe RS, Swartz MS, et al. (2006) Interrelationships of psychiatric symptom severity, medical comorbidity, and functioning in Schizophrenia. Psychiatr Serv 57: 1102-1109.

8. Folsom DP, McCahill M, Bartels SJ, Lindamer LA, Ganiats TG, et al. (2002) Medical Comorbidity and Receipt of Medical Care by Older Homeless People with Schizophrenia or Depression. Psychiatr Serv 53: 1456-1460.
9. Bermudes RA, Keck PE, Welge JA (2006) The prevalence of the Metabolic Syndrome in Psychiatric Inpatients with Primary Psychotic and Mood Disorders. Psychosomatics 47: 491-497.

10. Kamara SG, Peterson PD, Dennis JL (1998) Prevalence of Physical Illness Among Psychiatric Inpatients Who Die of Natural Causes. Psychiatr Serv 49: 788-793.

11. Knutsen E, DuRand C (1991) Previously unrecognized physical illness in psychiatric patients. Psychiatr Serv 42:182-186.

12. Subramaniam M, Chong SA, Pek E (2003) Diabetes mellitus and impaired glucose tolerance in patients with schizophrenia. 48: 345-347.

13. De Hert M, van Winkel R, Van Eyck D (2006) Prevalence of diabetes, metabolic syndrome and metabolic abnormalities in schizophrenia over the course of the illness: a cross-sectional study. Clin Pract Epidemiol Ment Health 2: 14.

14. Parks J, Svendsen D, Singer P, Foti ME (2006) Morbidity and mortality in people with serious mental illness. National Association of State Mental Health Program Directors (NASMHPD) Medical Directors Council.

15. Kilbourne AM, Brar JS, Drayer RA, Xu X, Post EP (2007) Cardiovascular disease and metabolic risk factors in male patients with schizophrenia schizoaffective disorder, and bipolar disorder. Psychosomatics 48: 412-417.

16. Mezuk B, Eaton WW, Albrecht S, Golden SH (2008) Depression and type 2 diabetes over the lifespan: a meta-analysis. Diabetes Care 31: 2383-2390.

17. Khess CR, Dutta I, Chakrabarty I, Bhattacharya P, Das J, et al. (1998) Comorbidity in children with mental retardation. Indian J Psychiatry 40: 289-294. 